\title{
Review \\ Eph receptors in breast cancer: roles in tumor promotion and tumor suppression
}

\author{
David Vaught ${ }^{2}$, Dana M Brantley-Sieders ${ }^{1}$ and Jin Chen ${ }^{1-4}$
}

\author{
${ }^{1}$ Department of Medicine, Division of Rheumatology and Immunology, Vanderbilt University School of Medicine, Nashville, TN 37232, USA \\ ${ }^{2}$ Department of Cancer Biology, Vanderbilt University School of Medicine, Nashville, TN 37232, USA \\ ${ }^{3}$ Vanderbilt-Ingram Cancer Center, Vanderbilt University School of Medicine, Nashville, TN 37232, USA \\ ${ }^{4}$ Department of Cell \& Developmental Biology, Vanderbilt University School of Medicine, Nashville, TN 37232, USA
}

Corresponding author: Jin Chen, jin.chen@vanderbilt.edu

Published: 22 December 2008

This article is online at http://breast-cancer-research.com/content/10/6/217

(c) 2008 BioMed Central Ltd

\begin{abstract}
Eph receptor tyrosine kinase signaling regulates cancer initiation and metastatic progression through multiple mechanisms. Studies of tumor-cell-autonomous effects of Eph receptors demonstrate their dual roles in tumor suppression and tumor promotion. In addition, Eph molecules function in the tumor microenvironment, such as in vascular endothelial cells, influencing the ability of these molecules to promote carcinoma progression and metastasis. The complex nature of Eph receptor signaling and crosstalk with other receptor tyrosine kinases presents a unique challenge and an opportunity to develop therapeutic intervention strategies for targeting breast cancer.
\end{abstract}

\section{Introduction}

The Eph receptors comprise the largest family of receptor tyrosine kinases. The family is subdivided into class $A$ and class $B$, based on sequence homology and binding affinity for two distinct types of membrane-anchored ephrin ligands. Ephrins and Eph receptors are key regulators of physiological and pathological processes in development and disease (for reviews, see [1-6]). Expression of many of the Eph receptors is often elevated in a wide variety of tumors, including breast cancer, yet their precise roles in cancer are not well understood. Data from recent studies demonstrated that Eph receptors and ephrins function in both tumor cells and the tumor microenvironment, with dual roles in tumor suppression and tumor promotion. In this review we highlight key results in the area of Eph receptor expression, tumor biology, and therapeutics in breast cancer, with an emphasis on EphA2 and EphB4 receptors.

\section{Eph receptor in mammary gland development} Mammary epithelial morphogenesis is a complex developmental process during which an extensive network of
Breast Cancer Research 2008, 10:217 (doi:10.1186/bcr2207)

branched ducts forms from a rudimentary epithelial bud. This process, termed 'branching morphogenesis', is regulated by endocrine hormones and local paracrine interaction between the developing epithelial ducts and their adjacent mesenchymal stroma. Expression of multiple Eph family receptors and their ligands has been reported in the mammary gland. Ephrin-B2 is expressed on the luminal cells, and its receptor, EphB4, is expressed complementarily on myoepithelial cells in mice. The expression of EphB4 and ephrin-B2 is dependent on estrogen and is regulated during the estrus cycle [7]. Over-expression of EphB4 under the control of the mouse mammary tumor virus (MMTV) promoter/enhancer induced delayed development of the mammary epithelium at puberty and during pregnancy, with unscheduled epithelial apoptotic cell death during pregnancy and abnormal epithelial DNA synthesis at early postlactational involution, indicating an abnormal response to proliferative/apoptotic signals [8].

In addition to EphB4, developmentally controlled expression of EphA2 in the mammary epithelium has also been reported $[9,10]$. Loss of EphA2 receptor resulted in decreased penetration of mammary epithelium into fat pad, reduced epithelial proliferation, and inhibition of epithelial branching, suggesting a positive role for EphA2 during normal mammary gland development (Vaught and coworkers, unpublished data). EphA2 is also expressed in human mammary epithelial cells [11-14]. Fournier and coworkers analyzed gene expression in two nonmalignant human mammary epithelial cell lines in three-dimensional cultures. When these cells underwent growth arrest and differentiated into polarized acini, EphA2 levels were significantly decreased [15], consistent with the observation that EphA2 is expressed at a low level in normal mammary gland epithelium, whereas expression increases in breast cancer [3]. Indeed, analysis of

EGFR = epidermal growth factor receptor; MMTV = mouse mammary tumor virus; PI3K = phosphoinositide-3 kinase; siRNA = small interfering $\mathrm{RNA}$; VEGF = vascular endothelial growth factor. 
a set of 19 genes that were downregulated in differentiated acini of human mammary epithelial cells in three-dimensional cultures against two independent breast cancer microarray datasets revealed that increased EphA2 levels are associated with poor patient prognosis $[13,15]$. Taken together, these data suggest that EphA2 is required for mammary gland morphogenesis, and increased EphA2 expression in human breast cancer is associated with tumor cell malignancy and poor patient survival.

\section{Role of Eph receptors in breast cancer promotion}

In screens for new receptor tyrosine kinases in cancer, many Eph receptors were found to be over-expressed in multiple types of human tumors [1,3]. Of Eph receptors expressed in breast cancer $[11,12,16,17]$, EphA2 and EphB4 are the two that have been most extensively studied. EphA2 is expressed at low levels in normal human breast epithelium $[9,18]$ and over-expressed in $60 \%$ to $80 \%$ of breast cancers $[11,12,19]$ (Brantley-Sieders and Chen, unpublished data). Experimentally induced over-expression of EphA2 resulted in malignant transformation of nontransformed MCF10A breast cells and enhanced malignancy of pancreatic carcinoma cells $[12,20]$. Conversely, small interfering RNA (siRNA)-mediated inhibition of EphA2 expression impaired malignant progression of pancreatic, ovarian, and mesothelioma tumor cell lines, and over-expression of dominant-negative EphA2 constructs suppressed growth and metastasis of 4T1 metastatic mouse mammary adenocarcinoma cells in vivo [20-23]. To determine whether EphA2 plays a causative role in breast cancer initiation and metastatic progression, EphA2 knockout mice were crossed to MMTV-Neu transgenic animals that express a rat homolog of the ErbB2 receptor tyrosine kinase. Loss of EphA2 impairs both tumor initiation and lung metastasis in MMTV-Neu mice [24]. Similarly, EphB4 levels are also elevated in human breast cancer [17]. EphB4 knockdown inhibited breast cancer survival, migration, and invasion in vitro and tumor growth in a xenograft model in vivo [25]. Furthermore, over-expression of EphB4 in the mammary epithelium accelerates tumor onset and lung metastasis in MMTV-Neu animals [8]. Taken together, these data indicate a role for Eph receptor in tumor promotion.

The mechanisms regulating the oncogenic effects of Eph receptors are not entirely clear. In many instances, Eph receptors in tumor cells are under-phosphorylated in spite of over-expression. This could be due to increased activity of phosphotyrosine phosphatase or loss of E-cadherin in tumor cells. E-cadherin regulates cell surface localization of EphA2 and/or loss of cell-cell contacts prevent interaction with endogenous ephrin ligands [26-28]. Because both Eph receptors and ligands are membrane anchored and reside in separate microdomains on the cell surface [29,30], loss of cell-cell adhesion in tumor cells impairs activation of Eph receptor by ephrins on adjacent cells. Thus, the oncogenic activity of Eph receptors appears to be ligand independent.
High levels of EphA2 receptor have been shown to interact physically with both the epidermal growth factor receptor (EGFR) and ErbB2, promoting Erk and RhoA GTPase activity [24,31]. These data suggest that crosstalk between Eph receptor and other oncogenic pathways promotes tumor cell malignancy, possibly in an ephrin-independent manner. Furthermore, a high level of EphA2 was found to upregulate matrix metalloproteinase 2 [20,32] and extracellular matrix protein fibronectin [33]. Modulation of tumor cell interaction with the microenvironment may also contribute to Eph receptor function in tumor promotion.

\section{Role of Eph receptors in tumor suppression}

Many studies have demonstrated a role for Eph receptor in tumor suppression. Stimulation of EphA receptors with soluble ephrin-A1-Fc ligand reduced Erk phosphorylation in tumor cell lines, fibroblasts, and primary aortic endothelial cells, and suppressed growth of primary keratinocytes and prostate carcinoma cells [34,35]. Macrae and coworkers [35] also reported that treatment of human breast cancer cell lines with ephrin-A1-Fc attenuated epidermal growth factor mediated phosphorylation of Erk and inhibited transformation of NIH3T3 cells expressing v-erbB2. In addition, EphA2deficient gene-trap mice displayed increased susceptibility to chemical carcinogen-induced skin cancer, accompanied by increased tumor cell proliferation and phosphorylation of Erk [36]. These data suggest that ephrin-A-induced EphA2 receptor forward signaling inhibits tumor malignancy.

In addition to EphA2, EphB4 forward signaling also appears to inhibit tumor progression. Systemic delivery of ephrin-B2Fc inhibits the growth of MDA-MB-435 tumor xenografts [37]. EphB4 forward signaling apparently activates the $\mathrm{Abl} / \mathrm{Crk}$ pathway to inhibit tumor cell growth and motility in breast cancer cells [37]. Furthermore, EphB receptor signaling is also able to suppress tumor expansion in colon cancer. Over-expression of a dominant negative EphB2 cytoplasmic truncation mutant or knockout of EphB3 or ephrin-B1 in the intestinal epithelium significantly increases tumor numbers and tumor invasiveness in the APC ${ }^{\mathrm{min} /+}$ model $[38,39]$. EphB receptors have been proposed to compartmentalize the expansion of colon cancer cells through a mechanism dependent on E-cadherin-mediated adhesion [39].

In summary, ephrin-induced Eph receptor forward signaling in nontransformed mammary epithelial cells appears to transduce an inhibitory signal that may keep cells quiescent and noninvasive [34,35,37]. Upon tumor initiation, Eph receptor expression is upregulated by oncogenic signaling pathways such as the Ras/mitogen-activated protein kinase pathway in breast cancer or the Wnt- $\beta$-catenin pathway in colon cancer, whereas their ephrin ligands are often downregulated $[35,40]$ or unable to bind to receptor because of loss of cell-cell adhesion [28]. Crosstalk between elevated Eph receptors and other oncogenes, such as the ErbB family of receptor tyrosine kinases [24,31], leads to enhanced cell 


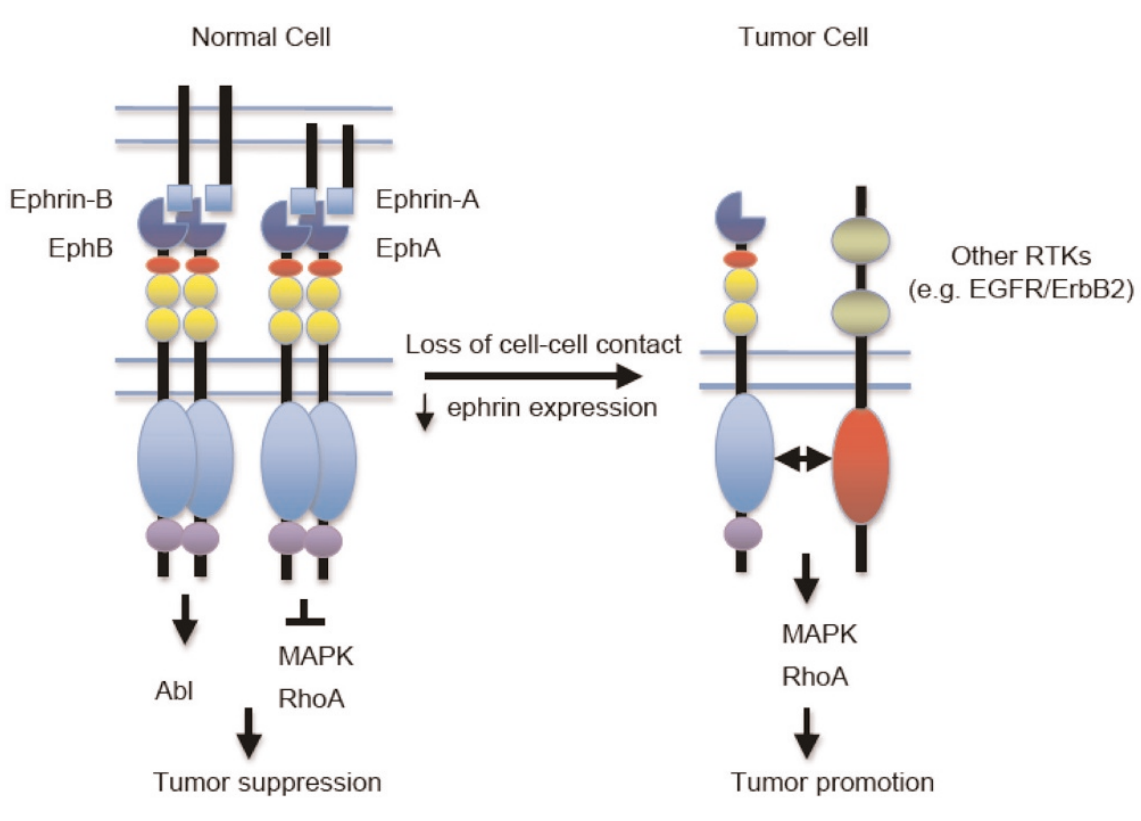

Working model for Eph receptor function in tumor promotion and tumor suppression. In normal cells, engagement of Eph receptors with ephrins on adjacent cells in trans induces receptor forward signaling, leading to inhibition of Ras/mitogen-activated protein kinase (MAPK) activity, or suppression of Crk activation via Abl kinase activity, and tumor suppression. In tumor cells, disruption of cell-cell junctions inhibits Eph receptor interaction with endogenous ephrins in trans. In addition, Eph receptors are often upregulated whereas ephrins are downregulated. Crosstalk between Eph receptors and other receptor tyrosine kinases such as ErbB2 and epidermal growth factor receptor (EGFR) results in increased activity of the Ras-MAPK pathway and the RhoA GTPase, and enhanced tumor malignancy.

proliferation and tumorigenesis, presumably independently of ephrin stimulation (Figure 1).

\section{Eph receptors and ephrins in tumor angiogenesis}

Tumor angiogenesis is critical for growth, survival, and malignant progression of tumors. Tumor vessels not only supply the nutrients and oxygen necessary for tumor cell growth and survival, but they also actively promote malignant progression by providing an entry point into the circulation for the dissemination of metastatic cells [41]. In addition to regulating developmental angiogenesis, Eph receptors and ephrins have also emerged as critical regulators of tumor angiogenesis. The first ligand discovered for the Eph receptors, ephrin-A1, is a tumor necrosis factor- $\alpha$ inducible gene in endothelial cells [42]. Early studies demonstrated that ephrin-A1 promotes angiogenic responses in vitro and corneal neovascularization in vivo [42]. Ephrin-A1 is expressed in developing embryonic and tumor vasculature $[11,18,43]$. More importantly, ephrin-A1 is further induced by hypoxia in tumors that are resistant to anti-vascular endothelial growth factor (VEGF) therapy [44]. Ephrin-A1 knockout mice were recently generated. Interestingly, ephrinA1-deficient mice survive to adulthood with only minor heart valve defects (Frieden and Chen, unpublished data), suggesting that loss of ephrin-A1 can be functionally compensated for in vascular development. It remains to be determined whether tumor angiogenesis is affected in these mice.

EphA2, a major receptor for ephrin-A1 in vascular endothelial cells, plays a significant role in promoting tumor angiogenesis. Implantation of tumor cells into the mammary gland of EphA2-deficient host mice results in reduced tumor volume, microvascular density, and lung metastasis. These findings suggest that loss of EphA2 in the tumor microenvironment impairs tumor angiogenesis and metastatic progression [24,45]. Indeed, EphA2-deficient vascular endothelial cells fail to migrate and assemble in response to angiogenic cues in vitro [46] and are unable to incorporate into tumor blood vessels when they are co-transplanted with tumor cells in vivo $[45,47]$, indicating a critical function for EphA2 in tumor angiogenesis.

In contrast to the complex effects of Eph signaling in tumor cells, Eph receptor signaling in vascular endothelial cells promotes tumor angiogenesis. Brantley-Sieders and coworkers [46] showed that EphA2 receptor forward signaling regulates endothelial cell migration and assembly through phosphoinositide-3 kinase (PI3K)-mediated Rac1 GTPase activation. A yeast two-hybrid screen for EphA2 interacting proteins revealed that Vav2 and Vav3 guanine nucleotide 
exchange factors are recruited to activated EphA2 receptor and subsequently elevate Rac1-GTP levels [48]. Loss of Vav2 and Vav3 inhibits Rac1 activity and ephrin-A1-induced angiogenic responses both in vitro and in vivo [48]. Furthermore, Fang and coworkers [47] mapped phosphorylated tyrosine residues of EphA2 in vascular endothelial cells. Ephrin-A1-induced phosphorylation of Y587 and Y593 in the EphA2 receptor recruits Vav2 and Vav3 exchange factors, whereas phosphorylation of $Y 734$ provides a docking site for the p85 regulatory subunit of PI3K. EphA2-null endothelial cells reconstituted with EphA2 mutants lacking these binding sites fail to activate Rac1 GTPase, are defective in cell migration and assembly in vitro, and are unable to incorporate into tumor vasculature in vivo. These findings suggest a critical role for these tyrosine phosphorylation sites in transducing EphA2 forward signaling in vascular endothelial cells and validated the involvement of PI3K-dependent activation of Vav exchange factors and Rac1 GTPase in ephrin-A1-induced angiogenesis.

Gene targeting studies have established ephrin-B2 and EphB4 as key regulators of embryonic vascular development $[49,50]$. Ephrin-B2 expression has also been observed in tumor vasculature in a variety of tumor types, suggesting that this ligand may regulate tumor neovascularization [51-53]. In support of this hypothesis, A375 melanomas form smaller, less vascularized tumors in the presence of the soluble, monomeric EphB4 extracellular domain in vivo [54]. Soluble EphB4 may act, at least in part, by preventing binding of tumor cell EphB receptors to ephrin-B2-positive endothelium, thus disrupting tumor angiogenesis. Further support for this hypothesis is provided by studies in which over-expression of a truncated cytoplasmic deletion EphB4 receptor construct produced increased tumor growth and vascularity in mammary tumors, probably through ephrin-B2 mediated reverse signaling in host endothelium [53]. Upregulation of ephrin-B1 expression has been reported in hepatocellular carcinoma, and over-expression of ephrin-B1 enhances tumor neovascularization in vivo [55]. Although proliferation of ephrin-B1 over-expressing cells was not affected in culture, soluble ephrin-B1-Fc enhanced endothelial cell proliferation and migration in vitro, suggesting that at least one function of ephrin-B1 in tumor progression involves facilitation of tumor angiogenesis $[55,56]$. Taken together, these studies reveal a critical role for B class receptors and ligands in tumor progression and vascular recruitment for multiple types of human cancer.

\section{Eph receptors as targets for breast cancer therapeutics}

Because Eph receptors are often over-expressed in malignant cancer, and reduction in Eph receptor levels was found to be efficacious in tumor inhibition in animal models, a wide range of therapeutic strategies targeting Eph receptors has been recently developed for cancer treatment. These approaches include activating monoclonal antibodies against
Eph receptors, ligand- or activating antibody-cytotoxin conjugates, siRNA, antagonistic peptides, small molecular inhibitors, and immunotherapy (Table 1).

Carles-Kinch and coworkers [57] first reported that activating monoclonal antibodies against EphA2 inhibited tumor growth in soft agar and prevented tubular network formation on Matrigel. Coffman and colleagues [58] subsequently showed that similar anti-EphA2 agonistic antibodies selectively bind epitopes on malignant cells and decrease tumor growth in xenograft tumor models. The mechanism of action of these antibodies appears to mimic ephrin ligands, inducing receptor phosphorylation and subsequent internalization and degradation [57,58]. However, it is not clear whether agonistic antibody-induced EphA2 receptor forward signaling also conveys an inhibitory signal to promote tumor suppression. Regardless, the ability of ephrins and anti-EphA2 antibodies to distinguish malignant from nonmalignant cells prompted the development of ligand- or agonistic antibodytoxin conjugates. Wykosky and coworkers [59] reported a novel cytotoxin composed of the ephrin-A1 ligand conjugated to a genetically modified bacterial toxin, namely Pseudomonas exotoxin A. Ephrin-A1-conjugates exhibit potent and dose-dependent killing of cancer cells that express high levels of the EphA2 receptor, including glioblastoma multiforme cells, as well as breast and prostate cancer cells. An anti-EphA2 antibody conjugated with the microtubule polymerization inhibitor monomethylauristatin phenylalanine (MMAF) has also been developed by Medlmmune Inc. (Gaithersburg, MD, USA). The conjugated antibody significantly inhibits tumor cell growth both in vitro and in vivo without any observable adverse effects [60]. These findings make ephrinA1- or antiEphA2-based cytotoxins a potentially attractive therapeutic strategy in the treatment of breast cancer.

siRNAs that specifically inhibit gene expression have rapidly become a powerful tool in both mechanistic studies and targeted therapeutics. It was previously reported that siRNAs directed against EphA2 resulted in decreased protein expression and decreased tumor growth in a pancreatic cancer xenograft model [20]. More recently, siRNAs against EphA2 were incorporated into packaging liposomes composed of the neutral lipid 1,2-dioleoyl-sn-glycero-3phosphatidylcholine (DOPC) for efficient in vivo delivery. Neutral liposome-coupled EphA2 siRNA reduced tumor growth in an orthotopic mouse model of ovarian cancer both in the presence and absence of paclitaxel [21,61], suggesting the feasibility of siRNA as a clinically applicable therapeutic approach.

Eph receptors and ephrins have emerged as critical regulators of tumor angiogenesis, making them attractive targets for inhibition of neovascularization [1,5]. More importantly, Eph/ephrin signaling provides a possible mechanism responsible for resistance to anti-VEGF therapy [44]. Soluble Eph receptors have been used to inhibit endogenous Eph 
Table 1

\begin{tabular}{|c|c|c|c|c|}
\hline Treatment & Target & Tumor & Institution & References \\
\hline Activating antibodies & EphA2 & Breast cancer & Medlmmune/AstraZeneca & {$[24,57,58]$} \\
\hline Antibody-conjugates & EphA2 & Prostate cancer, glioma & Medlmmune/AstraZeneca & {$[60]$} \\
\hline Ephrin-conjugates & EphA2 & Glioblastoma & Wake Forest University & [59] \\
\hline \multirow[t]{2}{*}{ siRNAs } & EphA2 & Ovarian cancer & MD Anderson & [21] \\
\hline & & Pancreatic cancer & Harvard & [20] \\
\hline \multirow[t]{3}{*}{ Soluble receptors } & EphA & Breast cancer & Immunex/Amgen & {$[18,62,63]$} \\
\hline & & Pancreatic cancer & Cephalon & \\
\hline & EphB & Melanoma & University of Frieburg & {$[54]$} \\
\hline \multirow[t]{3}{*}{ Inhibitory peptides } & EphB4 & Angiogenesis & Burnham Institute & {$[64,67,73]$} \\
\hline & EphB2 & & & [65] \\
\hline & EphA2 & & & {$[74]$} \\
\hline \multirow[t]{2}{*}{ Small molecule inhibitors } & EphA2 & Angiogenesis & Burnham Institute & {$[66]$} \\
\hline & EphA4 & & & \\
\hline \multirow[t]{2}{*}{ Immunotherapy } & EphA2 & Colon cancer & Osaka University & [68] \\
\hline & & Glioblastoma & University of Pittsburgh & [69] \\
\hline
\end{tabular}

receptor signaling in vascular endothelium and tumor angiogenesis in vivo $[18,54,62,63]$. More recently, the Pasquale laboratory has developed a peptide, TNYL-RAW, which competes with ephrin-B2 for binding to EphB4 receptor $[64,65]$. In addition, two isomeric small molecule compounds have been identified that selectively inhibit ephrin binding to EphA4 and EphA2 [66]. Both the EphB4 blocking peptide and EphA2/EphA4 antagonistic compounds inhibit Eph receptor phosphorylation and capillary-like tube formation in human umbilical vein endothelial cells $[66,67]$. This suggests that they can potentially serve as starting points from which to develop antiangiogenic therapies in cancer treatment.

In addition to being direct targets for therapeutic intervention, EphA2-derived peptides have been used in a dendritic cellbased vaccine for immunotherapy in glioblastoma multiforme and colon cancer [68-70]. Early studies showed that, in renal cell carcinoma, EphA2-derived peptides induced specific, tumor-reactive $\mathrm{CD}^{+}$and $\mathrm{CD}^{+}{ }^{+} \mathrm{T}$-cell responses. The reactivity of $\mathrm{CD}^{+} \mathrm{T}$ cells to EphA2 peptides was stronger in $T$ cells isolated from postsurgery disease-free patients than in those from patients with active disease, suggesting that the immune system of cancer patients actively monitors EphA2derived epitopes [70]. More recently, vaccination using dendritic cells pulsed with EphA2 peptides in a murine colon cancer model revealed that immunization inhibited the growth of MC38 tumors expressing EphA2, but did not have an effect on BL6 tumors that do not express EphA2 [68]. Furthermore, Hatano and coworkers [69] reported that stimu- lation of peripheral blood mononuclear cells from glioma patients and control healthy donors with dendritic cells loaded with EphA2 peptide elicited an antigen-specific cytotoxic T cell response. These preliminary results demonstrate that EphA2-derived epitopes may represent important candidate vaccines to be tested in clinical trials for the treatment of malignant cancers.

\section{Conclusions}

Eph receptor expression is often increased in human cancer, including breast cancer. The available evidence suggests that ligand-induced Eph receptor signaling in tumor cells plays a role in tumor suppression, whereas ligand-independent Eph receptor signaling functions in tumor promotion. Further investigation into molecular pathways that may be differentially regulated by EphA2 activation in response to endogenous ephrin ligands versus activation by association with other receptor tyrosine kinases, such as ErbB2, could provide insight into the differential effects of EphA2 signaling in breast cancer. Moreover, analysis of EphA2 and ErbB2/ EGFR co-expression in human breast cancer samples, coupled with genetic evidence suggesting that EphA2 cooperates with ErbB2 to promote tumor progression in mice [24], may provide a rationale for combining EphA2-targeted therapies with inhibitors of ErbB2/EGFR signaling in patients that express both receptors.

For EphB4, expression patterns and function of B class Eph receptors in intestinal epithelial patterning and tumorigenesis 
provide a model for elucidating the roles played by this and other EphB receptors in breast cancer. Expression and functional studies suggest that EphB/ephrin-B family members coordinate positional patterning of specific cell types in intestinal epithelium to prevent intermingling, and expression of several $B$ class molecules are regulated by the Wnt/ $\beta$ catenin signaling pathway in the gut $[40,71]$. Complementary expression of Ephrin-B2 on luminal cells and EphB4 on myoepithelial cells in the mouse mammary gland [7] could function to maintain a boundary between these cell types, similar to what is observed in the intestinal models. Moreover, because several members of the Wnt signaling pathway have been implicated in mammary gland development and breast cancer (for review see [72]), similar upregulation of EphB receptors by Wnt/ $\beta$-catenin could contribute to breast cancer progression. Further research is required to test these hypotheses.

In addition to a tumor cell autonomous role, Eph receptor also regulates important tumor-host interactions, notably in stimulation of tumor angiogenesis during tumor progression. As such, targeting Eph receptors holds both promises and challenges for therapeutic intervention in breast cancer. The effects of Eph receptors on both tumor cells and tumor microenvironment provide a unique therapeutic opportunity to block multiple steps in tumor progression. At the same time, the nature of bidirectional signaling of the Eph/ephrin system, and contribution of cell-type and context-dependent factors to the multi-faceted role of Eph receptors in cancer cells may complicate the development of effective therapeutic agents. Further research in dissecting bidirectional signaling and the context-dependent role of Eph receptors in cancer is essential for developing successful therapeutic strategies.

\section{Competing interests}

We acknowledge that we have received grant funding from Medlmmune, Inc. within the past 3 years, and have submitted a provisional patent application with Medlmmune concerning therapeutic targeting of EphA2.

\section{Acknowledgements}

We apologize for our failure to cite many important studies because of space limitation. This work was supported by grants from the NIH (CA95004 and CA114301 to JC and CA1179151 to DB) and the US Department of Defense (W81XWH-08-1-0249 to DV).

\section{References}

1. Pasquale EB: Eph-ephrin bidirectional signaling in physiology and disease. Cell 2008, 133:38-52.

2. Pasquale EB: Developmental cell biology: Eph receptor signalling casts a wide net on cell behaviour. Nat Rev Mol Cell Biol 2005, 6:462-475.

3. Ireton $\mathrm{R} \mathrm{C}$, Chen J: EphA2 receptor tyrosine kinase as a promising target for cancer therapeutics. Curr Cancer Drug Targets 2005, 5:149-157.

4. Brantley-Sieders D, Schmidt S, Parker M, Chen J: Eph receptor tyrosine kinases in tumor and tumor microenvironment. Curr Pharm Des 2004, 10:3431-3442.

5. Brantley-Sieders D, Chen J: Eph receptor tyrosine kinases in angiogenesis: from development to disease. Angiogenesis 2004, 7:17-28.
6. Kullander $\mathrm{K}$, Klein R: Mechanisms and functions of Eph and ephrin signaling. Nat Rev Mol Cell Biol 2002, 3:475.

7. Nikolova Z, Djonov V, Zuercher G, Andres A, Ziemiecki A: Celltype specific and estrogen dependent expression of the receptor tyrosine kinase EphB4 and its ligand ephrin-B2 during mammary gland morphogenesis. J. Cell Sci, 111: 2741-2751.

8. Munarini N, Jager R, Abderhalden S, Zuercher G, Rohrbach V, Loercher S, Pfanner-Meyer B, Andres AC, Ziemiecki A: Altered mammary epithelial development, pattern formation and involution in transgenic mice expressing the EphB4 receptor tyrosine kinase. J Cell Sci 2002, 115:25-37.

9. Kouros-Mehr H, Werb Z: Candidate regulators of mammary branching morphogenesis identified by genome-wide transcript analysis. Dev Dyn 2006, 235:3404-3412.

10. Andres A-C, Reid HH, Zurcher G, Blaschke RJ, Albrecht D, Ziemiecki A: Expression of two novel eph-related receptor protein tyrosine kinases in mammary gland development and carcinogenesis. Oncogene 1994, 9:1461-1467.

11. Ogawa $K$, Pasqualini $R$, Lindberg RA, Kain $R$, Freeman $A L$, Pasquale EB: The ephrin-A1 ligand and its receptor, EphA2, are expressed during tumor neovascularization. Oncogene 2000, 19:6043-6052

12. Zelinski DP, Zantek ND, Stewart JC, Irizarry AR, Kinch MS: EphA2 overexpression causes tumorigenesis of mammary epithelial cells. Cancer Res 2001, 61:2301-2306.

13. Martin KJ, Patrick DR, Bissell MJ, Fournier MV: Prognostic breast cancer signature identified from 3D culture model accurately predicts clinical outcome across independent datasets. PLOS ONE 2008, 3:e2994.

14. Fang WB, Ireton RC, Zhuang G, Takahashi T, Reynolds A, Chen $\mathrm{J}$ : Overexpression of EPHA2 receptor destabilizes adherens junctions via a RhoA-dependent mechanism. J Cell Sci 2008, 121:358-368.

15. Fournier MV, Martin KJ, Kenny PA, Xhaja K, Bosch I, Yaswen P, Bissell MJ: Gene expression signature in organized and growth-arrested mammary acini predicts good outcome in breast cancer. Cancer Res 2006, 66:7095-7102.

16. Fox BP, Kandpal RP: Invasiveness of breast carcinoma cells and transcript profile: Eph receptors and ephrin ligands as molecular markers of potential diagnostic and prognostic application. Biochem Biophys Res Commun 2004, 318:882892.

17. Wu Q, Suo Z, Risberg B, Karlsson MG, Villman K, Nesland JM: Expression of Ephb2 and Ephb4 in breast carcinoma. Pathol Oncol Res 2004, 10:26-33.

18. Brantley DM, Cheng N, Thompson EJ, Lin Q, Brekken RA, Thorpe PE, Muraoka RS, Cerretti DP, Pozzi A, Jackson D, Lin C, Chen J: Soluble EphA receptors inhibit tumor angiogenesis and progression in vivo. Oncogene 2002, 21:7011-7026.

19. Pan M: Overexpression of EphA2 gene in invasive human breast cancer and its association with hormone receptor status [ASCO Annual Meeting Proceedings]. J Clin Oncol 2005, 23:9583.

20. Duxbury MS, Ito H, Zinner MJ, Ashley SW, Whang EE: EphA2: a determinant of malignant cellular behavior and a potential therapeutic target in pancreatic adenocarcinoma. Oncogene 2004, 23:1448-1456.

21. Landen CN Jr, Chavez-Reyes A, Bucana C, Schmandt R, Deavers MT, Lopez-Berestein G, Sood AK: Therapeutic EphA2 gene targeting in vivo using neutral liposomal small interfering RNA delivery. Cancer Res 2005, 65:6910-6918.

22. Nasreen N, Mohammed KA, Antony VB: Silencing the receptor EphA2 suppresses the growth and haptotaxis of malignant mesothelioma cells. Cancer 2006, 107:2425-2435.

23. Fang WB, Brantley-Sieders DM, Parker MA, Reith AD, Chen J: A kinase-dependent role for EphA2 receptor in promoting tumor growth and metastasis. Oncogene 2005, 24:7859-7868.

24. Brantley-Sieders DM, Zhuang G, Hicks D, Fang WB, Hwang Y, Cates JM, Coffman K, Jackson D, Bruckheimer E, Muraoka-Cook $\mathrm{RS}$, Chen J: The receptor tyrosine kinase EphA2 promotes mammary adenocarcinoma tumorigenesis and metastatic progression in mice by amplifying ErbB2 signaling. J Clin Invest 2008, 118:64-78.

25. Kumar SR, Singh J, Xia G, Krasnoperov V, Hassanieh L, Ley EJ, Scehnet J, Kumar NG, Hawes D, Press MF, Weaver FA, Gill PS: Receptor tyrosine kinase EphB4 is a survival factor in breast 
cancer. Am J Pathol 2006, 169:279-293.

26. Kikawa K, Vidale DR, Van Etten RL, Kinch MS: Regulation of the EphA2 kinase by the low molecular weight tyrosine phosphatase induces transformation. J Biol Chem 2002, 277: 39274-39279.

27. Orsulic S, Kemler R: Expression of Eph receptors and ephrins is differentially regulated by E-cadherin. J Cell Sci 2000, 113: 1793-1802.

28. Zantek ND, Azimi M, Fedor-Chaiken M, Wang B, Brackenbury R, Kinch MS: E-cadherin regulates the function of the EphA2 receptor tyrosine kinase. Cell Growth Differ 1999, 10:629-638.

29. Marquardt T, Shirasaki R, Ghosh S, Andrews SE, Carter N, Hunter T, Pfaff SL: Coexpressed EphA receptors and ephrin-A ligands mediate opposing actions on growth cone navigation from distinct membrane domains. Cell 2005, 121:127-139.

30. Noren NK, Pasquale EB: Paradoxes of the EphB4 receptor in cancer. Cancer Res 2007, 67:3994-3997.

31. Larsen AB, Pedersen MW, Stockhausen MT, Grandal MV, van Deurs B, Poulsen HS: Activation of the EGFR gene target EphA2 inhibits epidermal growth factor-induced cancer cell motility. Mol Cancer Res 2007, 5:283-293.

32. Duxbury MS, Ito H, Zinner MJ, Ashley SW, Whang EE: Ligation of EphA2 by ephrin-A1-Fc inhibits pancreatic adenocarcinoma cellular invasiveness. Biochem Biophys Res Commun 2004, 320:1096-1102.

33. Hu M, Carles-Kinch KL, Zelinski DP, Kinch MS: EphA2 induction of fibronectin creates a permissive microenvironment for malignant cells. Mol Cancer Res 2004, 2:533-540.

34. Miao H, Wei BR, Peehl DM, Li Q, Alexandrou T, Schelling JR, Rhim JS, Sedor JR, Burnett E, Wang B: Activation of EphA receptor tyrosine kinase inhibits the Ras/MAPK pathway. Nat Cell Biol 2001, 13:527-530.

35. Macrae M, Neve RM, Rodriguez-Viciana P, Haqq C, Yeh J, Chen C, Gray JW, McCormick F: A conditional feedback loop regulates Ras activity through EphA2. Cancer Cell 2005, 8:111118

36. Guo H, Miao H, Gerber L, Singh J, Denning MF, Gilliam AC, Wang B: Disruption of EphA2 receptor tyrosine kinase leads to increased susceptibility to carcinogenesis in mouse skin. Cancer Res 2006, 66:7050-7058.

37. Noren NK, Foos G, Hauser CA, Pasquale EB: The EphB4 receptor suppresses breast cancer cell tumorigenicity through an Abl-Crk pathway. Nat Cell Biol 2006, 8:815-825.

38. Batlle E, Bacani J, Begthel H, Jonkeer S, Gregorieff A, van de Born M, Malats N, Sancho E, Boon E, Pawson T, Gallinger S, Pals $\mathrm{S}$, Clevers $\mathrm{H}$ : EphB receptor activity suppresses colorectal cancer progression. Nature 2005, 435:1126-1130.

39. Cortina C, Palomo-Ponce S, Iglesias M, Fernandez-Masip JL, Vivancos A, Whissell G, Huma M, Peiro N, Gallego L, Jonkheer S, Davy A, Lloreta J, Sancho E, Batlle E: EphB-ephrin-B interactions suppress colorectal cancer progression by compartmentalizing tumor cells. Nat Genet 2007, 39:1376-1383.

40. Batlle $E$, Henderson JT, Beghtel $H$, van den Born MM, Sancho $E$, Huls G, Meeldijk J, Robertson J, van de Wetering M, Pawson T, Clevers $\mathrm{H}$ : Beta-catenin and TCF mediate cell positioning in the intestinal epithelium by controlling the expression of EphB/ephrinB. Cell 2002, 111:251-263.

41. Folkman J: Role of angiogenesis in tumor growth and metastasis. Semin Oncol 2002, 29:15-18.

42. Pandey A, Shao H, Marks RM, Polverini PJ, Dixit VM: Role of B61, the ligand for the Eck receptor tyrosine kinase, in TNF-alphainduced angiogenesis. Science 1995, 268:567-569.

43. McBride JL, Ruiz JC: EphrinA1 is expressed at sites of vascular development in the mouse. Mech Dev 1998, 77:201-204.

44. Casanovas O, Hicklin DJ, Bergers G, Hanahan D: Drug resistance by evasion of antiangiogenic targeting of VEGF signaling in late-stage pancreatic islet tumors. Cancer Cell 2005, 8: 299-309.

45. Brantley-Sieders DM, Fang WB, Hicks D, Koyama T, Shyr Y, Chen J: Impaired tumor microenvironment in EphA2-deficient mice inhibits tumor angiogenesis and metastatic progression. FASEB J 2005, 19:1884-1886.

46. Brantley-Sieders D, Caughron J, Hicks D, Pozzi A, Ruiz JC, Chen $\mathrm{J}$ : EphA2 receptor tyrosine kinase regulates endothelial cell migration and assembly through phosphoinositide 3-kinasemediated Rac1 GTPase activation. J Cell Sci 2004, 117:20372049.
47. Fang WB, Brantley-Sieders DM, Hwang Y, Ham AJ, Chen J: Identification and functional analysis of phosphorylated tyrosine residues within EphA2 receptor tyrosine kinase. J Biol Chem 2008, 283:16017-16026.

48. Hunter SG, Zhuang G, Brantley-Sieders DM, Swatt W, Cowan $\mathrm{CW}$, Chen J: Essential role of Vav family guanine nucleotide exchange factors in EphA receptor-mmediated angiogenesis. Mol Cell Biol, 26:4830-4842.

49. Wang HU, Chen ZF, Anderson DJ: Molecular distinction and angiogenic interaction between embryonic arteries and veins revealed by ephrin-B2 and its receptor Eph-B4. Cell 1998, 93: 741-753.

50. Adams RH, Wilkinson GA, Weiss C, Diella F, Gale NW, Deutsch $U$, Risau W, Klein R: Roles of ephrinB ligands and EphB receptors in cardiovascular development: demarcation of arterial/ venous domains, vascular morphogenesis, and sprouting angiogenesis. Genes Dev 1999, 3:295-306.

51. Gale NW, Baluk P, Pan L, Kwan M, Holash J, DeChiara TM, McDonald DM, Yancopoulos GD: Ephrin-B2 selectively marks arterial vessels and neovascularization sites in the adult, with expression in both endothelial and smooth-muscle cells. Dev Biol 2001, 230:151-160.

52. Shin D, Garcia-Cardena G, Hayashi S, Gerety S, Asahara T, Stavrakis G, Isner J, Folkman J, Gimbrone MA Jr, Anderson DJ: Expression of ephrinB2 identifies a stable genetic difference between arterial and venous vascular smooth muscle as well as endothelial cells, and marks subsets of microvessels at sites of adult neovascularization. Dev Biol 2001, 230:139-150.

53. Noren NK, Lu M, Freeman AL, Koolpe M, Pasquale EB: Interplay between EphB4 on tumor cells and vascular ephrin-B2 regulates tumor growth. Proc Natl Acad Sci USA 2004, 101:55835588

54. Martiny-Baron G, Korff T, Schaffner F, Esser N, Eggstein S, Marme D, Augustin HG: Inhibition of tumor growth and angiogenesis by soluble EphB4. Neoplasia 2004, 6:248-257.

55. Sawai Y, Tamura S, Fukui K, Ito N, Imanaka K, Saeki A, Sakuda S, Kiso S, Matsuzawa Y: Expression of ephrin-B1 in hepatocellular carcinoma: possible involvement in neovascularization. Hepatol 2003, 39:991-996.

56. Nagashima K, Endo A, Ogita H, Kawana A, Yamagishi A, Kitabatake A, Matsuda M, Mochizuki N: Adaptor protein Crk is required for ephrin-B1-induced membrane ruffling and focal complex assembly of human aortic endothelial cells. Mol Biol Cell 2002, 13:4231-4242.

57. Carles-Kinch K, Kilpatrick KE, Stewart JC, Kinch MS: Antibody targeting of the EphA2 tyrosine kinase inhibits malignant cell behavior. Cancer Res 2002, 62:2840-2847.

58. Coffman KT, Hu M, Carles-Kinch K, Tice D, Donacki N, Munyon K, Kifle G, Woods R, Langermann S, Kiener PA, Kinch MS: Differential EphA2 epitope display on normal versus malignant cells. Cancer Res 2003, 63:7907-7912.

59. Wykosky J, Gibo DM, Debinski W: A novel, potent, and specific ephrinA1-based cytotoxin against EphA2 receptor expressing tumor cells. Mol Cancer Ther 2007, 6:3208-3218.

60. Jackson D, Gooya J, Mao S, Kinneer K, Xu L, Camara M, Fazenbaker C, Fleming R, Swamynathan S, Meyer D, Senter PD, Gao C, Wu H, Kinch MS, Coats S, Kiener PA, Tice DA: A human antibody-drug conjugate targeting EphA2 inhibits tumor growth in vivo. Cancer Res 2008, 68:22.

61. Landen CN, Merritt WM, Mangala LS, Sanguino AM, Bucana C, Lu C, Lin YG, Han LY, Kamat AA, Schmandt R, Coleman RL, Gershenson DM, Lopez-Berestein G, Sood AK: Intraperitoneal delivery of liposomal siRNA for therapy of advanced ovarian cancer. Cancer Biol Ther 2006, 5:1708-1713.

62. Dobrzanski P, Hunter K, Jones-Bonlin S, Chang H, Robinson C, Pritchard S, Zhao H, Ruggeri B: Antiangiogenic and antitumor efficacy of EphA2 receptor antagonist. Cancer Res 2004, 64: 910-919, 2004

63. Cheng N, Brantley D, Liu H, Fanslow W, Cerretti DP, Reith AD, Jackson D, Chen J: Inhibition of VEGF-dependent multi-stage carcinogenesis by soluble EphA receptors. Neoplasia 2003, 5: 445-456.

64. Koolpe M, Burgess R, Dail M, Pasquale EB: EphB receptorbinding peptides identified by phage display enable design of an antagonist with ephrin-like affinity. J Biol Chem 2005, 280: 17301-17311.

65. Chrencik JE, Brooun A, Recht MI, Nicola G, Davis LK, Abagyan R 
Widmer H, Pasquale EB, Kuhn P: Three-dimensional structure of the EphB2 receptor in complex with an antagonistic peptide reveals a novel mode of inhibition. J Biol Chem 2007, 282:36505-36513.

66. Noberini R, Koolpe M, Peddibhotla S, Dahl R, Su Y, Cosford ND, Roth GP, Pasquale EB: Small molecules can selectively inhibit ephrin binding to the EphA4 and EphA2 receptors. J Biol Chem 2008, 283:29461-29472.

67. Salvucci O, de la Luz Sierra M, Martina JA, McCormick PJ, Tosato G: EphB2 and EphB4 receptors forward signaling promotes SDF-1-induced endothelial cell chemotaxis and branching remodeling. Blood 2006, 108:2914-2922.

68. Yamaguchi S, Tatsumi T, Takehara T, Sakamori R, Uemura A, Mizushima T, Ohkawa K, Storkus WJ, Hayashi N: Immunotherapy of murine colon cancer using receptor tyrosine kinase EphA2-derived peptide-pulsed dendritic cell vaccines. Cancer 2007, 110:1469-1477.

69. Hatano M, Kuwashima N, Tatsumi T, Dusak JE, Nishimura F, Reilly KM, Storkus WJ, Okada H: Vaccination with EphA2-derived T cell-epitopes promotes immunity against both EphA2expressing and EphA2-negative tumors. J Trans/ Med 2004, 2: 40.

70. Tatsumi T, Herrem CJ, Olson WC, Finke JH, Bukowski RM, Kinch $\mathrm{MS}$, Ranieri E, Storkus WJ: Disease stage variation in $\mathrm{CD}^{+}$and CD8 ${ }^{+}$T-cell reactivity to the receptor tyrosine kinase EphA2 in patients with renal cell carcinoma. Cancer Res 2003, 63:44814489.

71. van de Wetering $M$, Sancho E, Verweij C, de Lau W, Oving I, Hurlstone A, van der Horn K, Batlle E, Coudreuse D, Haramis A, Tjon-Pon-Fong M, Moerer P, van den Born M, Soete G, Pals S, Eilers M, Medema R, Clevers $\mathrm{H}$ : The $\beta$-catenin/TCF-4 complex imposes a crypt progenitor phenotype on colorectal cancer cells. Cell 2002, 111:241-250.

72. Mohinta $\mathrm{S}, \mathrm{Wu} \mathrm{H}$, Chaurasia $\mathrm{P}$, Watabe $\mathrm{K}$ : Wnt pathway and breast cancer. Front Biosci 2007, 12:4020-4033.

73. Chrencik JE, Brooun A, Recht MI, Kraus ML, Koolpe M, Kolatkar AR, Bruce RH, Martiny-Baron G, Widmer H, Pasquale EB, Kuhn $P$ : Structure and thermodynamic characterization of the EphB4/Ephrin-B2 antagonist peptide complex reveals the determinants for receptor specificity. Structure 2006, 14:321330.

74. Koolpe M, Dail M, Pasquale EB: An ephrin mimetic peptide that selectively targets the EphA2 receptor. J Biol Chem 2002, 277:46974-46979. 